\title{
The effect of milrinone on the intraoperative hemodynamics during off-pump coronary bypass surgery in patients with an elevated echocardiographic index of the ventricular filling pressure
}

\author{
Jong Wook Song ${ }^{1,2}$, Youn Yi Jo ${ }^{1,2}$, Na Hyung Jun ${ }^{1,2}$, Ha Kyoung Kim ${ }^{1}$, and Young Lan Kwak ${ }^{1,2}$ \\ ${ }^{1}$ Department of Anesthesiology and Pain Medicine, ${ }^{2}$ Anesthesia and Pain Research Institute, Yonsei University College of Medicine, \\ Seoul, Korea
}

Background: Hemodynamic derangement during off-pump coronary artery bypass surgery (OPCAB) is mainly attributed to impaired filling and diastolic dysfunction. An elevated ratio of the mitral velocity to the early-diastolic velocity of the mitral annulus (E/e' $>15)$ is a relatively new indicator of diastolic function, and this was reported to be associated with impaired hemodynamics during OPCAB. We investigated the efficacy of milrinone on the perioperative hemodynamics and short term outcomes of patients with an E/e' $>15$ and who underwent OPCAB.

Methods: The patients were randomly allocated into either group C (control, $n=31)$ or group $M(n=31)$ and they were treated with the same amount of either normal saline or milrinone $(0.5 \mu \mathrm{g} / \mathrm{kg} / \mathrm{min})$ without bolus loading after completion of internal mammary artery harvest until the end of operation. Hemodynamic measurements were recorded after the induction of anesthesia (T1), $5 \mathrm{~min}$ after starting each distal anastomosis of the left anterior descending artery (T2), left circumflex artery (T3) and right coronary artery (T4), and 5 min after sternum closure (T5). Results: The mixed venous oxygen saturation $\left(\mathrm{SvO}_{2}\right)$ was lower through $\mathrm{T} 2-\mathrm{T} 4$ compared to the baseline value in both groups, while the degree of the decrease was significantly less in group $\mathrm{M}$ than that in group $\mathrm{C}$. The other hemodynamic variables, the operative data and the postoperative outcomes were similar between the two groups.

Conclusions: Intraoperative infusion of milrinone did not significantly improve the perioperative hemodynamics and the subsequent short term outcomes for the patients with preexisting diastolic dysfunction as represented by an elevated E/e' value, although it reduced the degree of decrease of the $\mathrm{SvO}_{2}$ during OPCAB. (Korean J Anesthesiol 2011; 60: 185-191)

Key Words: Diastolic dysfunction, E/e', Milrinone, Off-pump coronary artery bypass surgery, Perioperative hemodynamics.

Received: June 4, 2010. Revised: 1st, July 8, 2010; 2nd, July 28, 2010. Accepted: August 11, 2010.

Corresponding author: Young Lan Kwak, M.D., Ph.D., Department of Anesthesiology and Pain Medicine, Yonsei University College of Medicine, 134, Shinchon-dong, Seodaemun-gu, Seoul 120-752, Korea. Tel: 82-2-2228-8513, Fax: 82-2-364-2951, E-mail: ylkwak@yuhs.ac This study was supported by faculy research grant (6-2006-0084) of Yonsei University College of Medicine 2006.

(c) This is an open-access article distributed under the terms of the Creative Commons Attribution Non-Commercial License (http:// creativecommons.org/licenses/by-nc/3.0/), which permits unrestricted non-commercial use, distribution, and reproduction in any medium, provided the original work is properly cited. 


\section{Introduction}

Multivessel off-pump coronary artery bypass graft surgery $(\mathrm{OPCAB})$ has proven to be a practicable and safe alternative to on-pump coronary artery bypass graft surgery (CABG) since the technical improvements and advances of stabilization devices have facilitated the comparable safety and early graft patency of OPCAB [1]. Yet displacement of the heart for exposing the grafting site during OPCAB can result in hemodynamic derangement, which is mainly attributed to impaired filling and diastolic dysfunction [2]. Thus, patients with pre-existing diastolic dysfunction would theoretically be more prone to experience significant hemodynamic deterioration when undergoing OPCAB.

Among the various variables affecting the diastolic function, the ratio of the early transmitral flow velocity to the early diastolic velocity of the mitral annulus (E/e') is a relatively new indicator of the diastolic function and it is well correlated with the left ventricular filling pressure [3]. In numerous studies, an E/e' greater than 15 has been used to accurately detect an elevated left ventricular filling pressure $[3,4]$. It was reported that patients with an elevated $\mathrm{E} / \mathrm{e}^{\prime}$ were more prone to undergo a reduction of the cardiac index $(\mathrm{CI})$ and the mixed venous oxygen saturation $\left(\mathrm{SvO}_{2}\right)$ during OPCAB [5].

Milrinone is a phosphodiesterase III inhibitor and it is a noncatecholamine drug that acts independently of $\beta$-adrenergic receptors and the plasma catecholamine concentrations [6]. It does not significantly increase myocardial oxygen consumption [7] and it leads to lower myocardial oxygen consumption than is associated with the use of dobutamine [8]. Milrinone also has a direct vasodilating effect on arterial coronary bypass grafts [9] and it increases the grafted mammary artery flow after coronary artery bypass grafting [10]. When performing OPCAB, the administration of milrinone during the operation reduced the extent of the decrease of the cardiac index and the extent of mitral regurgitation [11-13]. Furthermore, milrinone has been suggested to improve the diastolic function as well as the systolic function [14-16]. Thus, we investigated whether intraoperatively infused milrinone would improve the intraoperative hemodynamics in patients with diastolic dysfunction, as represented by an elevated E/e' value, and who are undergoing OPCAB.

\section{Materials and Methods}

Those patients scheduled for OPCAB between January and December 2009 were enrolled after receiving approval from our Institutional Review Board and obtaining informed written consent from the patients. The inclusion criteria were patients with an E/e' value $>15$, and this was measured
1 day before elective OPCAB. The exclusion criteria were concomitant systolic dysfunction (a left ventricular ejection fraction less than $40 \%$ ) or mitral regurgitation $\geq$ Grade 2 , an emergency operation and being involved in other studies. The E/e' value was measured by a cardiologist using transthoracic echocardiography. From the apical four-chamber view, the early transmitral inflow velocity (E) was measured by pulsedwave Doppler with a sample volume of $1-2 \mathrm{~mm}$, and the early-diastolic velocity of the mitral annulus ( $\left.e^{\prime}\right)$ was measured by pulsed-wave Doppler tissue imaging of the septal mitral annulus with a sample volume of $2-4 \mathrm{~mm}$. Sixty-four patients who met the inclusion criteria were randomized into the two groups using computer-generated codes: those receiving intraoperative milrinone (group $\mathrm{M}$ ) and those receiving normal saline (group C). The group assignment for each patient was sealed in sequentially numbered, opaque envelopes. These envelopes were opened after induction of anesthesia and a nurse who is not involved in the anesthesia and postoperative care of the patients prepared milrinone or saline solution according to the group assignment. The patient characteristics were similar between the groups, except for the preoperative

Table 1. Patients' Characteristics

\begin{tabular}{|c|c|c|}
\hline & $\begin{array}{l}\text { Group C } \\
(\mathrm{n}=31)\end{array}$ & $\begin{array}{c}\text { Group M } \\
(\mathrm{n}=31)\end{array}$ \\
\hline Age (yr) & $65.7 \pm 7.9$ & $67.2 \pm 7.6$ \\
\hline Height (cm) & $162.9 \pm 10.2$ & $159.9 \pm 9.8$ \\
\hline Weight (kg) & $64.5 \pm 9.4$ & $63.5 \pm 10.5$ \\
\hline Gender (M/F) & $21 / 10$ & $14 / 17$ \\
\hline Preoperative Cr (mg/dl) & $1.50 \pm 1.74$ & $1.60 \pm 1.58$ \\
\hline COPD & 7 & 3 \\
\hline Diabetes & 20 & 17 \\
\hline Hypertension & 23 & 22 \\
\hline History of CVA & 3 & 3 \\
\hline CHF (NYHA $\geq \mathrm{III})$ & 10 & 13 \\
\hline \multicolumn{3}{|c|}{ Preoperative Echocardiography } \\
\hline $\operatorname{LVEF}(\%)$ & $51.5 \pm 16.7$ & $55.3 \pm 15.3$ \\
\hline Akinesia & 16 & 10 \\
\hline Thinning & 5 & 4 \\
\hline $\mathrm{E} / \mathrm{e}^{\prime}$ & $21 \pm 8$ & $21 \pm 6$ \\
\hline Lt main disease & 8 & 10 \\
\hline Acute coronary syndrome & 22 & 20 \\
\hline \multicolumn{3}{|l|}{ Preoperative medication } \\
\hline$\beta$-blocker & 25 & $17 *$ \\
\hline Calcium channel blocker & 11 & 17 \\
\hline ARB & 9 & 10 \\
\hline ACEi & 12 & 11 \\
\hline Diuretics & 12 & $5 *$ \\
\hline
\end{tabular}

Values are means \pm SDs or the number of patients. Cr:serum creatinine, COPD: chronic obstructive pulmonary disease, CVA: cerebrovascular accident, CHF: congestive heart failure, NYHA: New York Heart Association, LVEF: left ventricular ejection fraction, E/e': ratio of the mitral velocity to the early-diastolic velocity of the mitral annulus, ARB: angiotensin receptor blocker, ACEi: angiotensin converting enzyme inhibitor, ${ }^{*} \mathrm{P}<0.05$ versus Group $\mathrm{C}$. 
medications (Table 1). More patients in the group $\mathrm{C}$ received $\beta$-blockers $(\mathrm{P}<0.05)$ and diuretics $(\mathrm{P}<0.05)$, preoperatively.

All the patients were premedicated with $0.05-0.1 \mathrm{mg} / \mathrm{kg}$ of intramuscular morphine $1 \mathrm{~h}$ before operation. Before induction of general anesthesia, standard monitoring devices were applied, including a radial artery catheter and a pulmonary artery catheter (Swan-Ganz Combo $\mathrm{CCO} / \mathrm{SvO}_{2}$, Edwards Lifesciences LLC, USA), which was inserted through the right internal jugular vein and connected to an analysis system (Vigilance, Edwards Lifesciences LLC, USA) for continuous monitoring of the $\mathrm{CI}$ and $\mathrm{SvO}_{2}$. Anesthesia was induced with intravenous midazolam $(0.03-0.07 \mathrm{mg} / \mathrm{kg})$ and sufentanil $(1.5-2.0 \mu \mathrm{g} / \mathrm{kg})$. Neuromuscular block was achieved by administering rocuronium $(0.9 \mathrm{mg} / \mathrm{kg})$ and this was maintained with a continuous infusion of vecuronium $(1-2 \mu \mathrm{g} / \mathrm{kg} / \mathrm{min})$. The patients were intubated and mechanically ventilated with a tidal volume of $8 \mathrm{mg} / \mathrm{kg}$ and a positive end-expiratory pressure of $5 \mathrm{mmHg}$ at a rate of $8-12$ breaths/min. Maintenance of anesthesia was done with $0.8-1.5 \mathrm{vol} \%$ of sevoflurane in a $40 \%$ oxygen/air mixture and a continuous infusion of sufentanil $(0.5-1.5 \mu \mathrm{g} / \mathrm{kg} / \mathrm{h})$. Isosorbide dinitrate $0.5 \mu \mathrm{g} / \mathrm{kg} / \mathrm{min}$ was infused in all the patients.

After induction of anesthesia, a transesophageal echocardiography probe was inserted to assess the global cardiac function and to detect newly developed regional wall motion abnormalities. Intravascular fluid was administered to maintain the pulmonary capillary wedge pressure (PCWP) between 8 and $16 \mathrm{mmHg}$ according to the baseline values before enucleation of the heart and after completion of grafting. After completion of harvesting the left internal mammary artery, the patients in group $\mathrm{M}$ received $0.5 \mu \mathrm{g} / \mathrm{kg} / \mathrm{min}$ of milrinone intravenously until the end of the distal anastomosis, while the patients in group $\mathrm{C}$ received the same amount of saline intravenously for the same duration. During the period of heart displacement, crystalloid solution was infused at a fixed rate of $6 \mathrm{ml} / \mathrm{kg} / \mathrm{h}$, and the amount of blood lost and collected by a cell salvage device was replaced by an infusion of colloid solution. The blood salvaged by the cell salvage device was re-infused into the patient before the end of the surgery. During the period of heart displacement and grafting, a mean systemic arterial pressure (MAP) was maintained above $70 \mathrm{mmHg}$ with using either a $5-10^{\circ}$ Trendelenburg position or a norepinephrine (NE) infusion. In the case of a $\mathrm{SvO}_{2}<60 \%$ for more than 10 min, the development of mitral regurgitation $\geq$ Grade 3 with a concomitant increase in the mean pulmonary arterial pressure (MPAP) $>30 \mathrm{mmHg}$ or both, an attending anesthesiologist could break the code and milrinone could be infused at his or her discretion. Allogenic-packed red blood cells (pRBCs) were transfused to maintain the hematocrit (Hct) level around 25\% throughout the study period. The central temperature measured by a pulmonary artery catheter (PAC) was maintained above $36^{\circ} \mathrm{C}$ with a warm mattress, a forced warm air blanket and a fluid warmer as necessary. Emergency cardiopulmonary bypass was performed when the MAP remained lower than $50 \mathrm{mmHg}$ with an elevated MPAP despite volume loading and drug treatment, there was a change in the ST segment more than $4 \mathrm{~mm}$ during the coronary artery anastomosis or there was ventricular fibrillation that did not respond to cardioversion.

All the surgical procedures were performed by one surgeon. After a median sternotomy, the heart was displaced using posterior pericardial stitches, large gauze swabs and tissue stabilizer (Octopus, Medtronic Inc., USA). Vertical right pericardiotomy was also performed to minimize compression of the right ventricle. The sequence of grafting was first the left internal mammary artery was grafted to the left anterior descending coronary artery (LAD) and this is followed by grafting the left circumflex coronary artery (LCX) and the right coronary artery (RCA) by way of a composite Y graft consisting of a radial artery or saphenous vein with the left internal mammary artery. All the patients were transferred to the intensive care unit (ICU) after the surgery. The postoperative care of the patients, including decisions for extubation and discharge from the ICU, was conducted according to the standard ICU protocols of our institution by the ICU staff, which was not aware of the study groups of the patients.

The assessed operative data was the number of grafts, the total distal graft reconstruction time, the amount of infused fluid, the urine output and transfusion, the amount of NE infused during grafting and the number of patients who needed intraoperative vasopressin use.

The hemodynamic variables obtained from the PAC and arterial line were recorded 15 minutes after the induction of anesthesia (T1), 10 minutes after stabilizer application for LAD grafting (T2), at the time of LCx grafting (T3) and RCA grafting (T4) and 15 minutes after sternum closure (T5). The hemodynamic data included the $\mathrm{SvO}_{2}$, CI, HR, MAP, central venous pressure (CVP), MPAP and right ventricular ejection fraction (RVEF). The number of patients with any episode of $\mathrm{CI}<2.0 \mathrm{~L} / \mathrm{min} / \mathrm{m}^{2}$ and $/$ or $\mathrm{SvO}_{2}<60 \%$ during distal grafting was recorded. In the ICU, the highest postoperative creatin kinase (CK)-MB value and the number of patients requiring inotropic support were recorded. The following postoperative complications during hospitalization were recorded; acute renal failure requiring dialysis, atrial fibrillation, myocardial infarction, stroke, acute kidney injury (serum creatinine elevation $>0.3 \mathrm{mg} / \mathrm{dl}$ or $>50 \%$ from the baseline), reoperation, infection and prolonged ventilation $(>48 \mathrm{~h})$. The duration of the ICU stay and postoperative hospital stay and the mortality were also recorded.

Twenty-seven patients were required in each group for $95 \%$ 
power to detect a $0.5 \mathrm{~L} / \mathrm{min} / \mathrm{m}^{2}$ difference in the CI between the groups with a SD of $0.5 \mathrm{~L} / \mathrm{min} / \mathrm{m}^{2}$ and an $\alpha$ value of 0.05 , and the sample size was set at 32 patients in each group when considering a $10 \%$ failure rate for data collection. All the data is expressed as means \pm SDs or the number of patients. The data was analyzed using $\chi^{2}$ tests, Fisher's exact test or independent t-tests as appropriate. The hemodynamic data was analyzed by repeated measures of ANOVA. Post-hoc tests were conducted with Bonferroni adjustment. The statistical analyses were performed using SAS 9.1.3 (Institute Inc., Cary, NC, USA). A P value $<0.05$ was considered statistically significant.

Table 2. Operative Data

\begin{tabular}{lcc}
\hline & $\begin{array}{c}\text { Group C } \\
(\mathrm{n}=31)\end{array}$ & $\begin{array}{c}\text { Group M } \\
(\mathrm{n}=31)\end{array}$ \\
\hline Number of grafts $(1 / 2 / 3 / 4 / 5)$ & $0 / 3 / 14 / 12 / 2$ & $0 / 7 / 18 / 5 / 1$ \\
Total graft reconstruction time (min) & $33 \pm 7$ & $31 \pm 8$ \\
NE infused during grafting ( $\mu \mathrm{g})$ & $197 \pm 110$ & $174 \pm 105$ \\
Intraoperative vasopressin use & 21 & 20 \\
Hematocrit (\%) & & \\
$\quad$ Post-induction & $32 \pm 4$ & $31 \pm 3$ \\
$\quad$ Before LAD grafting & $28 \pm 4$ & $27 \pm 3$ \\
$\quad$ After sternum closure & $27 \pm 3$ & $26 \pm 2$ \\
Input & & \\
$\quad$ Crystalloid (ml) & $2,560 \pm 658$ & $2,487 \pm 899$ \\
$\quad$ Colloid (ml) & $1,255 \pm 240$ & $1,235 \pm 221$ \\
$\quad$ pRBC (ml) & $276 \pm 322$ & $314 \pm 333$ \\
$\quad$ Salvaged blood (ml) & $213 \pm 111$ & $253 \pm 184$ \\
Urine output (ml) & $560 \pm 321$ & $529 \pm 465$ \\
\hline
\end{tabular}

Values are means \pm SDs or the number of patients. NE: norepinephrine, LAD: left anterior descending coronary artery, pRBC: packed red blood cells.

\section{Results}

One patient in group $\mathrm{M}$ was converted to emergency cardiopulmonary bypass due to hemodynamic instability and one patient in group $\mathrm{C}$ received milrinone infusion during distal LCx and RCA grafting due to an extremely lower $\mathrm{SvO}_{2}$ with concomitantly increased mitral regurgitation. A total of 62 patients completed the study.

The operative data, including the number of grafts, the total distal graft reconstruction time, the amount of NE infused during distal grafting, the number of patients requiring vasopressin, the hematocrit and the intraoperative input and output were not significantly different between the groups (Table 2).

The baseline hemodynamic variables at $\mathrm{T} 1$ showed no differences between the groups. The $\mathrm{SvO}_{2}$ was significantly decreased at T2, T3 and T4 compared to the baseline value at $\mathrm{T} 1$ in both groups, but the degree of decrease in the $\mathrm{SvO}_{2}$ was significantly less in group $\mathrm{M}$ than that in group C (Table 3, P < 0.05). The CI was reduced at T3 and T4, the CVP and MPAP were increased at T2, T3 and T4, the HR was increased at T4 and the RVEF was significantly decreased at $\mathrm{T} 3, \mathrm{~T} 4$ and $\mathrm{T} 5$ compared to the baseline value at $\mathrm{T} 1$ in both groups (all $\mathrm{P}<0.05$ ). However, the degree of changes of the CI and the other hemodynamic variables, except the $\mathrm{SvO}_{2}$, were similar between the groups (Table 3). The number of patients with an episode of a CI less than $2.0 \mathrm{~L} / \mathrm{min} / \mathrm{m}^{2}$ were 19 in group $\mathrm{C}$ and 15 in group $\mathrm{M}(\mathrm{P}>$ $0.05)$, and the number of patients with a episode of a $\mathrm{SvO}_{2}$ less than $60 \%$ were 9 in group $C$ and 4 in group $\mathrm{M}(\mathrm{P}>0.05)$.

The highest postoperative CK-MB concentrations during the ICU stay and the number of patients requiring vasopressors

Table 3. Hemodynamic Data

\begin{tabular}{|c|c|c|c|c|c|c|}
\hline & Group & $\mathrm{T} 1$ & $\mathrm{~T} 2$ & T3 & $\mathrm{T} 4$ & T5 \\
\hline \multirow[t]{2}{*}{$\mathrm{SvO}_{2}(\%)$} & Group C & $77 \pm 6$ & $68 \pm 11$ & $64 \pm 8$ & $67 \pm 8$ & $71 \pm 4$ \\
\hline & Group M & $77 \pm 5$ & $72 \pm 9 *$ & $70 \pm 8^{*}$ & $71 \pm 8^{*}$ & $74 \pm 6^{*}$ \\
\hline \multirow[t]{2}{*}{$\mathrm{CI}\left(\mathrm{L} / \mathrm{min} / \mathrm{m}^{2}\right)$} & Group C & $2.7 \pm 0.7$ & $2.5 \pm 0.5$ & $1.9 \pm 0.4$ & $2.0 \pm 0.4$ & $2.5 \pm 0.4$ \\
\hline & Group M & $2.5 \pm 0.4$ & $2.5 \pm 0.7$ & $2.1 \pm 0.5$ & $2.1 \pm 0.3$ & $2.6 \pm 0.7$ \\
\hline \multirow[t]{2}{*}{ HR (beats/min) } & Group C & $64 \pm 14$ & $65 \pm 10$ & $66 \pm 10$ & $66 \pm 9$ & $70 \pm 11$ \\
\hline & Group M & $61 \pm 10$ & $67 \pm 10$ & $67 \pm 15$ & $72 \pm 11$ & $74 \pm 13$ \\
\hline \multirow[t]{2}{*}{ MAP (mmHg) } & Group C & $69 \pm 9$ & $70 \pm 4$ & $69 \pm 7$ & $71 \pm 5$ & $70 \pm 11$ \\
\hline & Group M & $72 \pm 10$ & $71 \pm 7$ & $69 \pm 6$ & $68 \pm 7$ & $69 \pm 7$ \\
\hline \multirow[t]{2}{*}{ CVP (mmHg) } & Group C & $8 \pm 3$ & $10 \pm 3$ & $10 \pm 3$ & $11 \pm 3$ & $8 \pm 2$ \\
\hline & Group M & $9 \pm 3$ & $11 \pm 3$ & $10 \pm 3$ & $11 \pm 3$ & $8 \pm 3$ \\
\hline \multirow[t]{2}{*}{ MPAP (mmHg) } & Group C & $18 \pm 4$ & $21 \pm 4$ & $21 \pm 4$ & $21 \pm 5$ & $20 \pm 4$ \\
\hline & Group M & $18 \pm 5$ & $23 \pm 6$ & $21 \pm 5$ & $20 \pm 6$ & $18 \pm 4$ \\
\hline \multirow[t]{2}{*}{ RVEF (\%) } & Group C & $34 \pm 10$ & $29 \pm 5$ & $26 \pm 8$ & $27 \pm 8$ & $28 \pm 6$ \\
\hline & Group M & $32 \pm 7$ & $30 \pm 7$ & $27 \pm 7$ & $26 \pm 8$ & $30 \pm 6$ \\
\hline
\end{tabular}

Values are means \pm SDs. $\mathrm{SvO}_{2}$ : mixed venous oxygen saturation, CI: cardiac index, HR: heart rate, MAP: mean arterial pressure, CVP: central venous pressure, MPAP: mean pulmonary arterial pressure, RVEF: right ventricular ejection fraction. T1: 15 min after induction of anesthesia, T2: 10 min after applying stabilizer for left anterior descending coronary artery grafting, T3: left circumflex coronary artery grafting, T4: right coronary artery grafting, T5: 15 min after sternum closure. ${ }^{*} \mathrm{P}<0.05$ a significantly lesser degree of a decrease from T1 as compared to the value for Group C. 
Table 4. Postoperative Data

\begin{tabular}{lcc}
\hline & $\begin{array}{c}\text { Group C } \\
(\mathrm{n}=31)\end{array}$ & $\begin{array}{c}\text { Group M } \\
(\mathrm{n}=31)\end{array}$ \\
\hline Vasopressor in ICU & 12 & 17 \\
Inotropics in ICU & 6 & 10 \\
Highest postoperative CK-MB (ng/ml) & $9.8 \pm 5.7$ & $9.6 \pm 8.1$ \\
Postoperative complications & & \\
$\quad$ Dialysis & 1 & 3 \\
$\quad$ Atrial fibrillation & 0 & 1 \\
$\quad$ Myocardial infarction & 2 & 1 \\
$\quad$ Stroke & 0 & 1 \\
$\quad$ Acute kidney injury & 3 & 4 \\
$\quad$ Re-operation & 0 & 2 \\
Infection & 2 & 3 \\
$\quad$ Intubation $>$ 48 h & 1 & 3 \\
ICU day & $3.2 \pm 1.6$ & $5.1 \pm 6.0$ \\
Hospital day & $19.1 \pm 21.2$ & $16.0 \pm 7.0$ \\
Mortality & 1 & 1 \\
\hline
\end{tabular}

Values are means \pm SDs or the number of patients. ICU: intensive care unit.

and inotropic support during the ICU stay were not different between the groups (Table 4). The incidence of postoperative complications, the duration of the ICU and postoperative hospital stay and the mortality were not different between the groups (Table 4).

\section{Discussion}

In this prospective randomized controlled trial of OPCAB, we investigated whether a preemptive intravascular infusion of milrinone would improve the intraoperative hemodynamics and short term postoperative outcomes in patients with an elevated E/e' value, which implicated impaired diastolic function.

Hemodynamic instability during distal anastomosis is the most serious problem during OPCAB surgery. The resultant myocardial dysfunction after displacing the heart during an OPCAB procedure is mainly diastolic dysfunction [2] and it is directly related to the postoperative outcomes. Lifting and tilting the heart in order to expose the posterior or lateral walls displace the atria below the corresponding ventricles, and the result is an increase in the atrial pressure and size [17], and thus, higher than normal filling pressures are required to maintain ventricular filling [18]. A vertical positioning of the heart induces distortions of the mitral and tricuspid annuli that may result in either stenosis or regurgitation of the corresponding valve [19]. In addition, application of a stabilizer device restricts the regional myocardial wall motion [20]. These changes contribute to a decrease in preload and stroke volume, resulting in a reduced $\mathrm{CI}, \mathrm{SvO}_{2}$ and MAP, and especially during exposure of the posterior wall [2]. Thus, it could be expected that patients with diastolic dysfunction are at a risk of more severe hemodynamic deterioration.

While the systolic function can easily be described by the LVEF, which is a commonly used indicator of systolic function, there are no definite variables to assess diastolic filling despite the well known importance of the diastolic function. The E/e' value derived from tissue Doppler echocardiography has been recently demonstrated to be a relatively load-independent index, and this is well correlated well with the left ventricular filling pressures $[3,4]$. The E/e' value is also considered a reliable index for diagnosing diastolic dysfunction. Because the e' value reflects the rate of myocardial relaxation, E/e' may be a precise variable that reflects a directly measured left ventricular end-diastolic pressure in terms of the diastolic function. The correlation of the E/e' with LV filling has been validated in various conditions $[3,4]$. Increased morbidity and/or mortality after myocardial infarction were reported in patients with an elevated E/e' value $[21,22]$. Further, the patients in a previous study with an $\mathrm{E} / \mathrm{e}^{\prime}>15$ experienced more severe hemodynamic derangement during $\mathrm{OPCAB}$ in spite of the preserved systolic left ventricular function [5]. When performing OPCAB, it is thought that that improvement of the diastolic function in the patients with preoperative diastolic dysfunction, which is represented by an elevated E/e,' would be helpful to attenuate hemodynamic deterioration.

Milrinone has been shown to improve cardiac performance in patients who are undergoing cardiac surgery and it facilitates weaning from cardiopulmonary bypass $[23,24]$. Previous studies on patients who are undergoing OPCAB demonstrated that milrinone infusion was beneficial to minimize the decrease of the $\mathrm{CI}$ and $\mathrm{SvO}_{2}[11,12]$. It was also suggested that milrinone might improve the ventricular diastolic function in patients with congestive heart failure since ventricular relaxation, as well as contraction, is an energy-dependent process $[14,15]$. Yet several studies that have evaluated the lusitropic effect of milrinone in cardiac surgery have showed contradictory results. While milrinone administration after aortic declamping improved the diastolic function as assessed by acoustic quantification and the peak filling rate during coronary artery bypass surgery [16], it failed to demonstrate a favorable lusitropic effect in other studies [25-27]. Many factors might be associated with this controversy; differences in the type of underlying cardiac disease and operation, the varying degrees of preexisting diastolic dysfunction and the modality used to assess diastolic dysfunction. In this study, administration of milrinone did not significantly improve the $\mathrm{CI}$ and $\mathrm{SvO}_{2}$, which is unlike the previous studies, suggesting the lesser efficacy of milrinone in patients with preexisting diastolic dysfunction. The early studies that focused on patients with congestive heart failure have indicated that the lusitropic effect of milrinone also results 
from the indirect effects caused by afterload reduction, as well as the direct effect of an improved active relaxation rate [28]. However, specific findings of a reduced afterload in terms of a decreased MAP or systemic vascular resistance or an increased cardiac output or the use of vasopressors were not observed in group $\mathrm{M}$ in this study, which may have been associated with the possibility of a lower blood concentration of milrinone. In this study, milrinone was infused at a rate $0.5 \mu \mathrm{g} / \mathrm{kg} / \mathrm{min}$, which was reported to increase the $\mathrm{CO}$ without causing systemic hypotension during OPCAB [29]. Despite that a significant hemodynamic effect of milrinone was reported to appear within 30 minutes from the start of the infusion (without a bolus), the plasma concentration of a continuous infusion without a bolus reached the same level, at least after $1 \mathrm{~h}$, as the concentration of an infusion after bolus injection [30]. Considering that an average of 20-30 min was required to start distal grafting after internal mammary artery harvesting, the plasma concentration of milrinone would not reach the concentration necessary to produce significant afterload reduction during distal anastomosis.

Although the patients in group $\mathrm{M}$ showed a lesser decrease of the $\mathrm{SvO}_{2}$, the postoperative outcomes were not different between the groups. This could be partially explained by the fact that there was no difference in the number of patients with decreased CI or $\mathrm{SvO}_{2}$ below a critical level (CI $<2.0 \mathrm{~L} / \mathrm{min} / \mathrm{m}^{2}$, $\mathrm{SvO}_{2}<60 \%$ ) between the groups, and the sample size of this study may not have been large enough to detect differences in relatively uncommon postoperative complications. The ICU stay of group $\mathrm{M}$ tended to be a little longer than that of group $\mathrm{C}$, but there was one patient who stayed in the ICU for 34 days.

There are several limitations in this study. First, we did not measure the diastolic function intraoperatively. Direct assessment of the effect of milrinone on the systolic and diastolic heart function was not obtained and future studies should address this. Second, there were differences of the preoperative medication between the groups. More patients in group $\mathrm{C}$ were taking $\beta$-blockers. Although the preoperative use of $\beta$-blockers can result in intraoperative bradycardia and hypotension, the hemodynamic variables at post-induction showed no differences between the groups. Moreover, the effect of milrinone is independent of $\beta$-adrenergic receptor blockade [6], and so it is unlikely that the preoperative use of $\beta$-blockers has a significant influence on the effect of milrinone on the hemodynamics during grafting.

In conclusion, for the patient with preexisting diastolic dysfunction as assessed by an elevated E/e' value, a continuous infusion of milrinone without bolus loading was not beneficial to improve the hemodynamic variables during $\mathrm{OPCAB}$ and the short-term postoperative outcomes, although it reduced the extent of the decrease of the $\mathrm{SvO}_{2}$ during the operation.

\section{References}

1. Abu-Omar Y, Taggart DP. The present status of off-pump coronary artery bypass grafting. Eur J Cardiothorac Surg 2009; 36: 312-21.

2. Chassot PG, van der Linden P, Zaugg M, Mueller XM, Spahn DR. Off-pump coronary artery bypass surgery: physiology and anaesthetic management. Br J Anaesth 2004; 92: 400-13.

3. Ommen SR, Nishimura RA, Appleton CP, Miller FA, Oh JK, Redfield $\mathrm{MM}$, et al. Clinical utility of Doppler echocardiography and tissue Doppler imaging in the estimation of left ventricular filling pressures: a comparative simultaneous Doppler-catheterization study. Circulation 2000; 102: 1788-94.

4. Dokainish H, Zoghbi WA, Lakkis NM, Al-Bakshy F, Dhir M, Quinones MA, et al. Optimal noninvasive assessment of left ventricular filling pressures: a comparison of tissue Doppler echocardiography and B-type natriuretic peptide in patients with pulmonary artery catheters. Circulation 2004; 109: 2432-9.

5. Shim JK, Choi YS, Chun DH, Hong SW, Kim DH, Kwak YL. Relationship between echocardiographic index of ventricular filling pressure and intraoperative haemodynamic changes during offpump coronary bypass surgery. Br J Anaesth 2009; 102: 316-21.

6. Skoyles JR, Sherry KM. Pharmacology, mechanisms of action and uses of selective phosphodiesterase inhibitors. Br J Anaesth 1992; 68: 293-302.

7. Monrad ES, Baim DS, Smith HS, Lanoue A, Brauwald E, Grossman W. Effects of milrinone on coronary hemodynamics and myocardial energetics in patients with congestive heart failure. Circulation 1985; 71: 972-9.

8. Monrad ES, Baim DS, Smith HS, Lanoue AS. Milrinone, dobutamine, and nitroprusside: comparative effects on hemodynamics and myocardial energetics in patients with severe congestive heart failure. Circulation 1986; 73: III168-74.

9. Liu JJ, Doolan LA, Xie B, Chen JR, Buxton BF. Direct vasodilator effect of milrinone, an inotropic drug, on arterial coronary bypass grafts. J Thorac Cardiovasc Surg 1997; 113: 108-13.

10. Lobato EB, Urdaneta F, Martin TD, Gravenstein N. Effects of milrinone versus epinephrine on grafted internal mammary artery flow after cardiopulmonary bypass. J Cardiothorac Vasc Anesth 2000; 14: 9-11.

11. Kwak YL, Oh YJ, Shinn HK, Yoo KJ, Kim SH, Hong YW. Haemodynamic effects of a milrinone infusion without a bolus in patients undergoing off-pump coronary artery bypass graft surgery. Anaesthesia 2004; 59: 324-31.

12. Kwak YL, Oh YJ, Kim SH, Shin HK, Kim JY, Hong YW. Efficacy of pre-emptive milrinone in off-pump coronary artery bypass surgery: comparison between patients with a low and normal pre-graft cardiac index. Eur J Cardiothorac Surg 2004; 26: 687-93.

13. Omae T, Kakihana Y, Mastunaga A, Tsuneyoshi I, Kawasaki $\mathrm{K}$, Kanmura Y, et al. Hemodynamic changes during off-pump coronary artery bypass anastomosis in patients with coexisting mitral regurgitation: improvement with milrinone. Anesth Analg 2005; 101: 2-8.

14. Monrad ES, McKay RG, Baim DS, Colucci WS, Fifer MA, Heller GV, et al. Improvement in indexes of diastolic performance in patients with congestive heart failure treated with milrinone. Circulation 1984; 70: 1030-7. 
15. Felker GM, O'Connor CM. Inotropic therapy for heart failure: an evidence-based approach. Am Heart J 2001; 142: 393-401.

16. Axelsson B, Arbeus M, Magnuson A, Hultman J. Milrinone improves diastolic function in coronary artery bypass surgery as assessed by acoustic quantification and peak filling rate: a prospective randomized study. J Cardiothorac Vasc Anesth 2010; 24: 244-9.

17. Mathison M, Edgerton JR, Horswell JL, Akin JJ, Mack MJ. Analysis of hemodynamic changes during beating heart surgical procedures. Ann Thorac Surg 2000; 70: 1355-60; discussion 1360-1.

18. Nierich AP, Diephuis J, Jansen EW, Borst C, Knape JT. Heart displacement during off-pump CABG: how well is it tolerated? Ann Thorac Surg 2000; 70: 466-72.

19. George SJ, Al-Ruzzeh S, Amrani M. Mitral annulus distortion during beating heart surgery: a potential cause for hemodynamic disturbance--a three-dimensional echocardiography reconstruction study. Ann Thorac Surg 2002; 73: 1424-30.

20. Mishra M, Malhotra R, Mishra A, Meharwal ZS, Trehan N. Hemodynamic changes during displacement of the beating heart using epicardial stabilization for off-pump coronary artery bypass graft surgery. J Cardiothorac Vasc Anesth 2002; 16: 685-90.

21. Hillis GS, Møller JE, Pellikka PA, Gersh BJ, Wright RS, Ommen SR, et al. Noninvasive estimation of left ventricular filling pressure by E/e' is a powerful predictor of survival after acute myocardial infarction. J Am Coll Cardiol 2004; 43: 360-7.

22. Hillis GS, Ujino K, Mulvagh SL, Hagen ME, Oh JK. Echocardiographic indices of increased left ventricular filling pressure and dilation after acute myocardial infarction. J Am Soc Echocardiogr 2006; 19: 450-6.
23. Doolan LA, Jones EF, Kalman J, Buxton BF, Tonkin AM. A placebocontrolled trial verifying the efficacy of milrinone in weaning highrisk patients from cardiopulmonary bypass. J Cardiothorac Vasc Anesth 1997; 11: 37-41.

24. Kikura M, Levy JH, Michelsen LG, Shanewise JS, Bailey JM, Sadel $\mathrm{SM}$, et al. The effect of milrinone on hemodynamics and left ventricular function after emergence from cardiopulmonary bypass. Anesth Analg 1997; 85: 16-22.

25. Maslow AD, Regan MM, Schwartz C, Bert A, Singh A. Inotropes improve right heart function in patients undergoing aortic valve replacement for aortic stenosis. Anesth Analg 2004; 98: 891-902.

26. Lobato EB, Willert JL, Looke TD, Thomas J, Urdaneta F. Effects of milrinone versus epinephrine on left ventricular relaxation after cardiopulmonary bypass following myocardial revascularization: assessment by color m-mode and tissue Doppler. J Cardiothorac Vasc Anesth 2005; 19: 334-9.

27. Couture P, Denault AY, Pellerin M, Tardif JC. Milrinone enhances systolic, but not diastolic function during coronary artery bypass grafting surgery. Can J Anaesth 2007; 54: 509-22.

28. Krams R, McFalls E, van der Giessen WJ, Serruys PW, Verdoun PD, Roelandt J. Does intravenous milrinone have a direct effect on diastolic function? Am Heart J 1991; 121: 1951-5.

29. Shibata T, Suehiro S, Sasaki Y, Hosono M, Nishi S, Kinoshita H. Slow induction of milrinone after coronary artery bypass grafting. Ann Thorac Cardiovasc Surg 2001; 7: 23-7.

30. Baruch L, Patacsil P, Hameed A, Pina I, Loh E. Pharmacodynamic effects of milrinone with and without a bolus loading infusion. Am Heart J 2001; 141: 266-73. 